districts about a million women and 100000 men in the United Kingdom are living with easily treatable regular incontinence.

We thank Drs H Yoxall, R Davies, and all the doctors and staff of Blackbrook and Williton surgeries. We also thank Mrs Brown, continence adviser; Mrs Pomeroy, physiotherapist; Dr P Ewings for statistical advice; and Dr C Bowie and colleagues in the department of public health medicine, Somerset, for comments on earlier drafts.

1 Holst $\mathrm{K}$, Wilson PD. The prevalence of female urinary incontinence and reasons for not seeking treatment. $N Z$ Med $\mathcal{F} 1988 ; 101: 756-8$.

2 King's Fund. Action on incontinence. London: King's Fund, 1983. (Project paper No 43 .

3-Thomas TM, Plymat KR, Blannin J, Meade TW. Prevalence of urinary incontinence. BMF 1980;281:1243-5.

4 Feneley RC, Shepherd AM, Powell PH, Blannin J. Urinary incontinence: prevalence and needs. Brf Crol 1979;51:493-6.

5 Jolleys JV. Diagnosis and management of female urinary incontinence in general practice. F R Coll Gen Pract 1989;39:277-9.

6 Jarvis GJ, Millar DR. Controlled trial of bladder drill for detrusor instability. BMF 1980;281:1322-3.

7 Pengelly AW, Booth CM. A prospective trial of bladder training as treatment for detrusor instability. Br $\mathcal{F}$ Urol 1980;52:462-6.

8 Hilton P. Urinary incontinence in women. BMF 1987;295:426-32.

9 Brocklehurst JC, Fry J, Griffiths LL, Kalton G. Urinary infection and symptoms of dysuria in women aged 45-64 years. Age Ageing 1972;1:41-7.

10 Urinary incontinence in elderly patients. Lancet 1986;ii:1316-7.

11 Hall C, Castleden CM, Grove GJ. Fifty six continence advisers, one peripatetic teacher. BMF 1988;297:1181-2.
12 Mohide EA, Pringle DM, Robertson D, Chambers LW. Prevalence of urinary incontinence in patients receiving home care services. Can Med Assoc . 7 1988;139:953-6.

13 Bates P, Bradley WE, Glen E. Standardisation of terminology of lower urinar tract function. Urology 1977;9:237-41.

14 McGrother CW, Castleden CM, Duffin H, Clarke M. Provision of services for incontinent elderly people at home. 7 Epidemiol Community Health 1986;40: 134-8.

15 Castleden CM, Duffin HM, Asher MJ. Clinical and urodynamic studies in one hundred elderly incontinent patients. BMF 1981;282:1003-5.

16 Frankel SJ, Williams MH, Nanchahal K, Coast J. Epidemiologically based needs assessment. Total hip and total knee joint replacement. Bristol: Health Care Evaluation Unit, 1990.

17 Stanton SL, Cardozo LD. Surgical treatment of incontinence in elderly women. Surg Gynecol Obstet 1980;150:555-7.

18 Castleden CM, Duffin HM, Mitchell EP. The effect of physiotherapy on stres incontinence. Age Ageing 1984;13:235-7.

19 Harrison SM. Stress incontinence and the physiotherapist. Physiotherap 1983;69:144-7.

20 Jarvis GJ, Millar DR. Controlled trial of bladder drill for detrusor instability BMF 1980;281:1322-3.

21 Pengelly AW, Booth CM. A prospective trial of bladder training as treatmen for detrusor instability. Br $\mathcal{F}$ Urol 1980;52:463-6.

22 Sutherst J, Brown $M$, Shawer $M$. Assessing the severity of urinary incontinence in women by weighing perineal pads. Lancet 1981;i:1128-30.

23 Fantl JA, Harkins SW, Wyman JF, Choi SC, Taylor JR. Fluid loss quantitation test in women with urinary incontinence: a test-retest analysis. Obstet Gynecol 1987;70:739-43.

24 Henalla SM, Kirwin P, Castleden CM, Hutchins CJ, Breeson AJ. The effect of pelvic floor exercises in the treatment of urinary stress incontinence in pelvic floor exercises in the treatment of urinary stress incont
women at two hospitals. Br f Obstet Gynaecol 1988;95:602-6.

25 Smith NK. Continence advisory services in England. Health Trends 1988;20: $22-4$

(Accepted 17 fuly 1991)

\title{
The Future of General Practice
}

\section{Caring for larger lists}

\section{G N Marsh}

There is no reason why the average number of patients on the list of each general practitioner should not be about 4000 . At the moment the average is well under 2000 and tending to fall. The new general practice contract contains incentives for list sizes to grow, and the government is interested that they should do so to contain expenditure on the health service. But larger lists can also make good professional sense.

Caring for 4000 patients obviously depends on good organisation and well developed teams, and the first advantage of large lists is that patients will receive care from team members more skilled than general practitioners in various types of care. Thus why should a general practitioner spend time providing marriage guidance when this can be done more competently (and more cheaply) by a counsellor? Or why should general practitioners run well person clinics when this can be done efficiently by nurses trained to do that task. Similarly it is sensible for practice management to be carried out by managers, leaving doctors to get on with the tasks for which their training particularly suits them.

The other important professional advantage to large lists is that the general practitioners see the various manifestations of disease more often. Thus they may be better able than practitioners with smaller lists to maintain their skills at diagnosing and treating emergencies like myocardial infarction and abdominal pain, dealing with rarer clinical appearances, as well as becoming more experienced in the commoner chronic illnesses.

This paper looks at how general practitioners can manage large lists and reviews the now considerable body of evidence on how this may bring benefits.

\section{Norton Medical Centre Stockton on Tees TS20 1AN G N Marsh, FRCGP, general practitioner}

momentum. ${ }^{23}$ Sharing care with fellow professionals in a primary health care team is the main way of reducing doctors' work. The new contract stipulates that doctors must provide adequate, daily, access to their patients; nevertheless, one of their main functions is to direct patients to other members of their team. Psychological and social problems can be shared with fellow carers better informed in these areas. ${ }^{+}$Even for physical illness, once the diagnosis has been established and management organised, much of the continued care can be done by nurses..$^{5-8}$ Patients must also have direct access to team members who are not doctors. Each member of the team has an important role in running an efficient practice.

\section{ADMINISTRATIVE AND MANAGEMENT STAFF}

Efficient trained receptionists and clerks should ensure a steady flow of patients to the doctors, and provide them with instant access to well ordered records on paper or computer..$^{9}$ Informed receptionists can answer many patients' queries, advise them who to see, and convey messages to and from the doctor. The practice manager coordinates the team, and by working with the family health services authority, accountants, architects, and solicitors, can relieve doctors of most of their administrative work. ${ }^{11}{ }^{11}$ It is the manager who should have taken on the work resulting from the new contract and fundholding. ${ }^{12}$ Extra money is being paid to fundholding practices for more management staff.

\section{NURSING TEAM}

The nurses are the clinical powerhouse of the team. Effective traditional community nursing can reduce the doctors' load ${ }^{5-8}$ and information gained during home visits, particularly to elderly and chronically sick patients, can be shared with doctors, thus reducing the need for doctors to visit. Practical nursing can be delegated to less highly trained assistants, in theory Since the 1966 family doctor's charter' the grouping
of doctors and formation of teams has gathered 
Work of practice nurse, Norton Medical Centre, 1989

\begin{tabular}{lr|c}
\hline Type of work & No of patients & \% Of workload \\
\hline Preventive: & 5541 & \\
Well woman clinic & 1046 & \\
Cervical smears & 301 & 69 \\
Well man clinic & 1199 & \\
Tetanus and travel injections & 890 & \\
Immunisation & 445 & \\
Diagnostic & 220 & \\
Therapeutic work: & 180 & \\
Medical extra & 378 & \\
Surgical extra & 276 & \\
Miscellaneous injections & 117 & \\
Diabetes clinic & 251 & \\
Vascular clinic & & \\
Minor operations & 5817 & \\
\hline Total &
\end{tabular}

providing time for preventive and therapeutic clinics. Shortage of community nurses, however, means that doctors need to employ practice nurses for these clinics.

About two thirds of the workload of a practice nurse is preventive and a quarter therapeutic (table). In both aspects, nurses work to protocols and aim at more comprehensive and detailed care with less doctor involvement. Unlike nurse practitioners, they do not diagnose but this is an area capable of expansion..$^{6-10}$ A nurse responsible for advising on minor illnessesfor example self care of coughs, colds, diarrhoea, and aches and pains - could reduce doctors' work considerably. This role requires further experimentation and development.

Community midwives can provide continuing care of normal pregnancies, ${ }^{13}$ although a doctor needs to be available to deal with diagnostic problems, deviations from normal course, prescribing, and as occasional psychological support for the midwife and the mother. ${ }^{14}$ Trained family planning nurses can advise and assess women starting contraception and supervise its continuation ${ }^{2}$ and may also give preconception counselling and advice on the menopause and hormone replacement therapy.

Given consulting rooms and space for clinics and preventive groups, health visitors can monitor children's development as well as advising on and following up children's health problems. ${ }^{15}$ MacMillan nurses, who specialise in care of the dying, can mobilise community supporting services and liaise with hospices. ${ }^{16}$ Community psychiatric nurses can supervise their progress, monitor and modify treatment, and provide guidance and counselling for patients with acute and chronic psychiatric illness, ${ }^{1718}$ and psychogeriatric nurses can give similar care to patients aged over 65 , many of them with dementia.

Drug and alcohol misuse counsellors can supervise the continuing care of patients with these problems.

\section{OTHER TEAM MEMBERS}

Analyses of consultations have shown that general practitioners deal with numerous social problems. Such problems often envelop and aggravate clinical ones, but sometimes patients will consult about purely social matters. Having a social worker as part of the team to deal with problems of housing, finance, loneliness, grants, home helps, aids for the disabled, etc, reduces doctors' consultations. Concern and care about such problems by informed people also lessens morbidity.

Dietitians working with patients with diabetes, other conditions responsive to diet, and organic diseases aggravated by excess weight increase caring and reduce doctors' work. ${ }^{19}$

Annual assessments of the over $75 \mathrm{~s}$ can be done by an elderly care visitor ${ }^{2021}$ who is aware of the patient's recorded clinical problems and works to a social protocol.
Unhappy patients who are experiencing marital disharmony, other interpersonal conflict, or self image problems often produce long, difficult, and emotionally charged consultations. They may be more expertly handled by trained counsellors. ${ }^{22}$

Physiotherapy facilities speed recovery from acute musculoskeletal disease and reduce treatment..$^{23} \mathrm{~A}$ liaising optician can report on retinas of diabetic and hypertensive patients and assess squint.

Fundholding practices may wish to expand care by linking with acupuncturists, hypnotists, etc. Their training, expertise, and protocols would have to be scrutinised as problems of responsibility might arise. Another area for experimentation.

\section{Working as a team}

Shared premises and a comprehensive team record facilitate communication and the provision of team care. ${ }^{24}$ Day to day sharing of patients' clinical problems bonds team members, coordinates their work, and minimises duplication. Thus formal opportunities for communication are essential.

Most important is the daily get together of the doctors, nurses, health visitors, midwife, and practice manager. Counsellors, dietitians, social workers, etc may also attend these sessions occasionally.

Weekly multidisplinary lunch time clinical meetings (approved by the Postgraduate Education Authority), monthly team meetings, and occasional single disci- స pline meetings are also helpful. When working with $Z$ independent professional colleagues, it is more appropriate for general practitioners to act as coordinators rather than leaders. The patient's problem is paramount and those primarily responsible for that problem should lead the team in dealing with it.

\section{Home visits}

Although British general practice can be justifiably proud of home visiting, only three or four patients an hour can be seen at home compared with eight to 12 in the surgery. Between 1969 and 1980 the average $\overrightarrow{\vec{\rho}}$ number of home visits in the Northern region fell from nine to five a day..$^{24} \mathrm{New}$ visits fell by $32 \%$ and follow up $\supset$ visits for chronically ill patients by $50 \%$. The falls were attributed to sick people attending surgery more, more people having cars, and self certification. The increasing proportion of elderly people and the lack of use of nurses for visiting militated against greater falls. General practitioners felt that a quarter of the visits were unnecessary, and large interdoctor variations existed in visiting rates within the same area, same population, and even the same practice. For efficient care, patients must attend the surgery whenever $\tilde{N}$ possible so trained receptionists should offer immedi- $D$ ate appointments, choice of team members, and, increasingly importantly, telephone consultations. N Convenient parking for handicapped people and N corridors, doors, and toilets adequate for wheelchairs 0 are necessary. Tightly drawn practice boundaries minimise time spent driving cars for all team members.

Only 7\% of home visits in 1980 were followed up by nurses, yet ongoing assessment of illness is totally 0 appropriate for them. Similarly, health visitors can assess the care of sick children and midwives that of $\mathbb{\Omega}$ pregnant or puerperal mothers. Telephone assessment $\mathbb{\mathbb { D }}$ by the doctor can replace some visiting. Community nurses and midwives are not trained to diagnose so their role in new visits is limited, but with trained 0 receptionists collecting information on the telephone, they can follow up patients discharged from hospital $\frac{0}{7}$

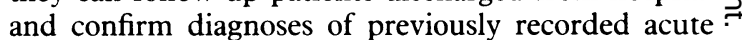
illness.

Despite the rise in the number of elderly people 


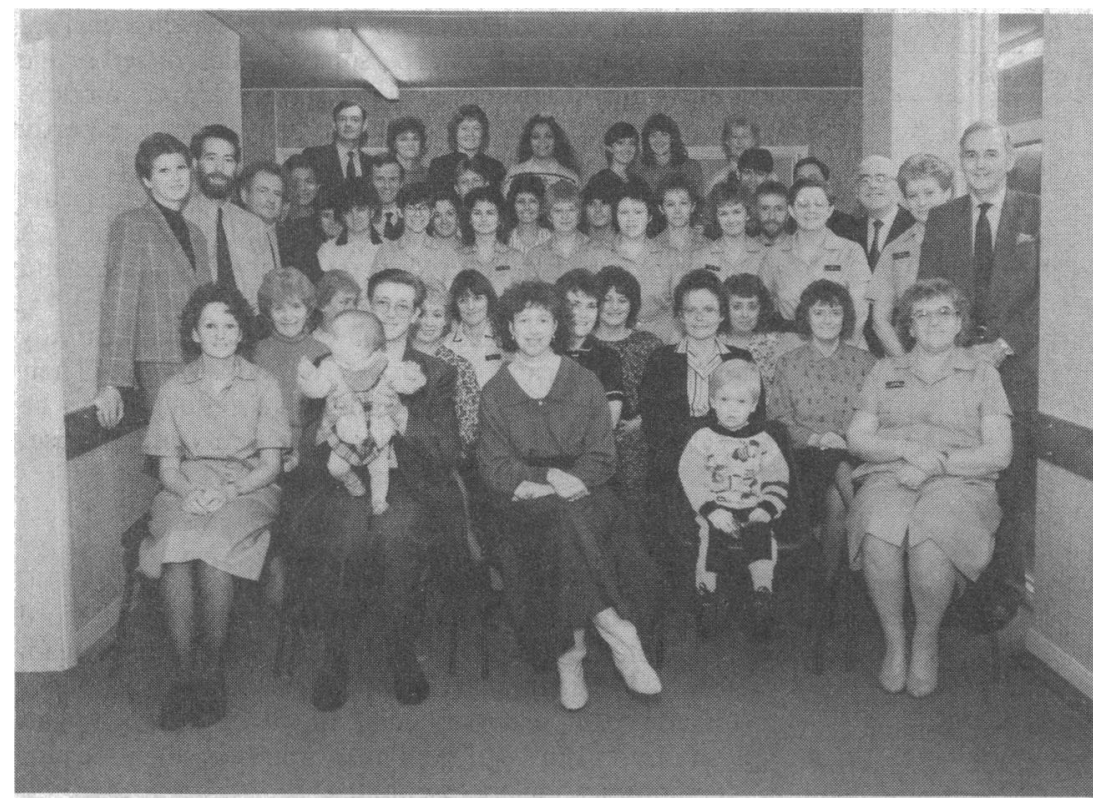

Primary health care team, Norton Medical Centre, surrounding one of the families in their care

between 1969 and 1980, visits initiated by doctors fel by $39 \%$. During that time, home helps, warden supervised accommodation, nursing homes, day hospitals, day centres, clubs, and workshops increased and the social value of a general practitioner's regular visit fell. Visiting of chronically sick housebound people can be shared by doctors, community nursing sisters, elderly care visitors, and psychogeriatric and community psychiatric nurses. With more time available, doctors can increase visits to patients who are seriously ill or dying and those in whom diagnosis is problematic. Such intensive home care can reduce referral rates to hospital.

Most people requesting late visits can receive telephone advice from the doctor. ${ }^{26}$

\section{Efficient management of clinical conditions}

Accurate diagnosis, appropriate treatment, and rapid cure are efficient ways of managing problems Telling patients the course of the illness and the time needed for its resolution minimises repeat consultations. Many illnesses recur and the earlier notes can expedite the consultation. Empirical treatment is increasingly acceptable. ${ }^{27}$ Unnecessary referral to hospital, with aggrandisement of illness, should be avoided. ${ }^{28}$

Many chronic illnesses-thyroid deficiency, pernicious anaemia, epilepsy, asthma, hypertension can be managed by nurses using protocols, and this often results in better care. ${ }^{29-32}$ Doctors have a large role at the onset of these illnesses but continuing supervision can be done mainly by nurses.

For the many recurring illnesses-urinary tract infection, vaginal discharge, napkin rash, eczema, varicose ulcers, warts-protocols for ongoing nursing care have not yet been developed. Nurse prescribing will facilitate this. Doctors and nurses must work to establish protocols and organise and audit the clinics. It also takes time to change patients' consulting habits but, once achieved, doctor consultations will decrease and overall standards improve.

\section{Not prescribing and prevention of iatrogenic disease}

Reassurance and health education are important components of the efficient response to self limiting minor illnesses. A common example is viral upper respiratory tract infections, for which doctors often prescribe inappropriate antibiotics, particularly in childhood. ${ }^{34}$ A prescription implicitly sanctions further consultation if the condition recurs. The high workload caused by epidemics of virus infections can be reduced by promoting self care. Recourse to pharmacists should be encouraged..$^{35} 36$

In patients with minor psychiatric conditions diagnosing worry rather than anxiety state, unhappi ness rather than depression, overconscientiousness rather than obsession, and fear rather than phobia $\overrightarrow{\mathrm{F}^{-}}$ might restrain doctors from treating. Patients with these conditions can be supported and cared for by other members of the primary health care team. Side effects, iatrogenic disease, addiction, and overdose from inappropriate prescription can produce considerable yet avoidable workload for doctors.

Practice formularies should include a "minicoepia" -a list of about 30 drugs which can treat about $80 \%$ of illnesses. ${ }^{37-39}$ By using it, mental effort is reduced, drugen familiarity increased, dosages and side effects becomes familiar, and generic names can be used; this system iș. not only efficient but also inexpensive.

\section{Repeat prescribing}

Speedy availability of drugs by repeat prescription $\vec{\omega}$ for continuing or recurrent episodes of illness is $\vec{\sim}$ popular with many patients. ${ }^{40}$ Long term conditionso (such as hypertension and epilepsy), remitting and exacerbating illnesses (hay fever and eczema), and ${ }^{\omega}$ illnesses characterised by repeated episodes (vaginalo discharge, backache, sciatica) are appropriate. Once the diagnosis has been established, understood by the $\overline{7}$ patient, and effective treatment established repeat黑 prescription rather than consultation is adequate for $\overrightarrow{0}$ continuing care or further episodes. Controls one number, frequency, and amount of drugs prescribed are essential. ${ }^{41}$ The repeat prescription system allowso patients to take greater responsibility for the care of their own illnesses.

\section{Preventive care}

Most preventive care can be, and is, implemented by staff other than doctors. ${ }^{42} 43$ Vaccinations for children, foreign travellers, influenza, and reaching immunisation targets in the new contract are the task of practice nurses and practice managers. Well person clinics and new patient checks can be run by practice nurses ${ }^{46}$ and yearly screening of elderly people, either at home or in 3 the surgery, by elderly care visitors. ${ }^{2021}$ The protocols used should arise from discussions between doctors 3 and the team members implementing them. Theo doctor is responsible for their accuracy and for ensuring that the care is properly given and plays ano occasional part (for example - physical examination of the newborn).

Appropriate training for all team members is essen- ${ }^{\circ}$ tial, as are legal safeguards. Coordination and auditing N్ట should be organised by the practice manager. Desktopo computers available to all team members at con sultations can highlight deficiencies in preventive care and so facilitate opportunistic screening. Special efforts by all team members can improve the care of 0 socially deprived and handicapped patients. ${ }^{45}$

\section{Personal lists}

Continued care by one doctor of one patient, and ideally one family, over many years facilitateso efficiency. ${ }^{46} 47$ A doctor in a large group cannot know alls the patients, but he or she can know some of them well. The patients also know their doctor and how he or she works - for example, antibiotics are not prescribed for virus infections and why consultation for self limiting 
illness is discouraged. Doctors with personal lists can record how they want, use their own diagnostic parameters, be consistent with therapy, and share care with team colleagues in ways their patients understand. Personal lists facilitate repeat prescriptions and, increasingly importantly, telephone consultations. Duplication of care is also avoided.

Personal lists mean that patients must have adequate access to their doctor, as insisted on in the new contract. One danger of a personal list is that the doctor can become out of date as there is little day to day peer review. Nevertheless, rota cover, interaction with trainees, meetings to discuss care, educational sessions, analysis of videoed consultations, establishment of protocols, increasing use of audit (including doctor to doctor comparisons) all serve to expose each doctor's care.

\section{Efficient records}

A comprehensive record available at each consultation is vital for efficient care. The Department of Health preventive care sheet contains a record of immunisation, cervical smear testing, blood pressure, and weight. Serial data on smoking, alcohol consumption, hobbies, exercise, can be added. ${ }^{24} \mathrm{~A}$ concise family history, including diabetes, thyroid disease, glaucoma, etc, and a summary of important illnesses and operations should be kept opposite the clinical record.

The preparation, overall condition, and auditing of records should be the responsibility of lay staff Attendance at clinics should be noted and put in the folder as well as records of health visitors, elderly care visitors, etc.

Some practices have already computerised parts of their manual records, and many more are doing so. ${ }^{4849}$ Computerisation of repeat prescribing has saved much in clerical time..$^{50}$ Many doctors now have desktop computers and a printer for issuing prescriptions. The practice formulary can be built into the computer as well as programs to preclude prescribing interacting drugs, those to which patients are allergic, or those that have side effects. Special programs are becoming available for use in vascular, diabetic, and other clinics.

\section{Efficient consulting room}

Doctors should sit in their consulting rooms so that they can watch the patient's entry, demeanor, and movements. Consultation across the desk corner gives access to the patient with one hand and to his "office facilities" with the other. History, pulse, examining limbs and throats, and listening to hearts can be done without leaving the chair.

Clinical equipment - pen torch, tongue depressors, auriscope, stethoscope, peak flow meter, sphygmomanometer, magnifying glass, scales, etc-should be kept by the general practitioner's desk and by the examination couch, and trays for gynaecological, proctoscopic, and eye examinations should be immediately available. Growth charts, height and weight data, and anatomical charts for explaining illness can be put on the walls.

\section{Working fast}

Frequent, short surgeries throughout the day are cost effective in time and energy. The six to seven minute average consultation time means that many consultations are three to five minutes and are usually for minor illness. Some opportunistic preventive care can be provided, although the numbers attending clinics run by nurses and recognised by family health services authorities suggest that the more structured and comprehensive care provided at them is becoming popular with patients.

In many consultations the patient is not examined, so taking a history over the telephone with comprehensive records available can be both efficient and accurate. Studies in countries where there is little or no home visiting are encouraging. ${ }^{51.53}$ All team members can set time aside to receive or return calls. Follow up consultations, communication with chronically sick? and housebound patients, giving results of tests, discussing a recurrence of illness can all be done on the telephone. Many out of hours emergencies, which? mostly concern patients already on treatment, can also음 be dealt with by telephone. ${ }^{26}$

\section{Involving patients}

Well informed patients will use their practice more $\overrightarrow{0}$ efficiently. ${ }^{3}$ The practice brochure should be a guide to $\vec{\omega}$ the use of the primary health care team. ${ }^{545}$ Littleo information is needed about doctors but a great dea $\bar{S}$ about the role of receptionists, nurses, midwives health visitors, counsellors, etc, as well as accounts of the clinics they run. The brochure can reinforce theos practice philosophy of self care of minor illness, use of pharmacists, limited need for drugs, avoidance of home visits, and encouraging use of the telephone. I $\overrightarrow{t \omega}$ can inform patients about self help groups for smokers, $\vec{\sim}$ people with asthma, psoriasis, eczema, etc; such? meetings expand patients' knowledge and decreasen their need to consult. Practice newsletters and annual ${ }^{\omega}$ reports can supplement this information.

\section{From greater efficiency to larger lists}

If all the above ideas were implemented generato practitioners should have time to expand services as well as to increase numbers on their lists. Between $1960^{\circ}$ and 1990 list sizes fell from about 3000 patients too $2000 .^{56}$ Whether doctors with smaller lists give better care has been debated, but the arguments have been confused as there are few parameters of quality. ${ }^{57-50}$ Doctors with smaller lists seem to do more preventive care, but this could be done by nurses. ${ }^{60}$

But has a personal list of 4000 patients any merits in itself? Apart from the greater return on the cost of medical education it provides more clinical experience? Seeing more patients increases knowledge resulting in fewer patients requiring hospital care. Surgeries and the many clinics provide a concentration of clinicab cases currently only found in hospital wards and. outpatient departments. Student and postgraduateo teaching could move into the community. There coulde be population based research.

But if the average number of patient-doctor consul tations fell from the current three to six a year to around two a year would patient satisfaction be less Reductions in attendance for minor self limiting illness would probably have little effect. Patients with serious illness would initially be seen just as often but perhapsw less in their convalescence and other team members would share in their continuing care. The averageo number of consultations with a health worker might be्D higher than it is now, and this could increase overalf satisfaction. The increased financial return for doctors 0 that might ensue from larger lists is of minor importance compared with these other benefits.

I thank the primary health care team of Norton Medicab Centre. Special thanks to Mrs Jane Arundell for secretaria help.

1 British Medical Association. Charter for the family doctor. London: BMA, 1966 2 Marsh GN, Kaim-Caudle P. Team care in general practice. London: Croom Helm, 1976 3 Marsh GN. The practice hrochure: a patient's guide to team care. BMJ
1980;281:730-2. 
4 Corney RH. Social work in general practice. $7 R$ Coll Gen Pract 1985; 35:291-2. 5 Garvie D. Sharing care with a practice nurse. Horizons; October 1990:10-2 6 Bowling A, Stilwell B, eds. The nurse in family practice. Practice nurses and nurse practitioners in primary health care. London: Saitari Press, 1988

7 Stilwell B, Greenfield S, Drury M, Hull FM. A nurse practitioner in general practice: working style and pattern of consultations. $\mathcal{F} R$ Coll Gen Pract 1987;37:154-7

8 Drury M, Greenfield S, Stilwell B, Hull FM. A nurse practitioner in general practice: patient perceptions and expectations. 7 R Coll Gen Pract 1988;38: 503-5.

9 Drury M, Collin M. The medical secretary's and receptionist's handbook. 5th ed. London: Baillière, 1986.

10 Drury M, ed. The new practice manager. Oxford: Radcliffe, 1990.

11 Pritchard P, Low K, Whalen M. Management in general practice. Oxford: Oxford University Press, 1984

12 Practice Outlook (February 1990). Fundholding special. Foumal for Practice Managers. AHCPA.

13 Royal College of Midwives. Report on the role and education of the future midwife in the United Kingdom. London: RCM, 1987.

14 Marsh GN. The "specialty" of general practitioner obstetrics. Lancet 1982;i: 669-72.

15 Marsh GN, Russell D, Russell IT. What do health visitors contribute to the care of children? A study in the north of England. $\mathcal{f} R$ Coll Gen Pract 1989;39:201-5.

16 Spilling R, ed. Terminal care at home. Oxford: Oxford University Press, 1986

17 Marks I. Controlled trial of psychiatric nurse therapists in primary care. $B M \mathcal{J}$ 1985;290:1181-4.

18 Robertson H, Sutt DJ. Community psychiatric nursing: a survey of patients and problems. I $R$ Coll Gen Pract 1985;35:130-2.

19 Massey-Lynch M. Dietitian in the practice. Practice Team 1985;No47:8-10.

20 McIntosh IB, Young M, Steward T. General practice geriatric surveillance scheme. Scott Med F 1988;33:332-3.

21 McLend J. Preventive care of the elderly. London: Royal College of General Practitioners, 1987. (Occasional paper No 35. )

22 McLeod J. The work of counsellors in general practice. London: Royal College of General Practitioners, 1989. (Occasional paper No 37.

23 Hacett GI, Hudson MF, Wylie JB, Jackson AD, Small KM, Harrison P, et al. Evaluation of the efficacy and acceptability to patients of a physiotherapist working in a health centre. $B M \mathcal{F}$ 1987;294:24-6.

24 Zander LI, Beresford SAA, Thomas P. Medical records in general practice. London: Royal College of General Practitioners, 1978. (Occasional paper No 5.)

25 Whewell J, Marsh GN, McNay RA. Changing pattern of home visiting in the north of England. BM7 1983;286:1259-61.

26 Marsh GN, Horne RA, Channing DM. A study of telephone advice in managing out-of-hours calls. $\mathcal{I} R$ Coll Gen Pract 1987;37:301-4.

27 Brown C, Rees WDW. Dyspepsia in general practice: try empirical treatment first and investigate patients who do not respond. $B M \mathcal{F}$ 1990;300:829-30.

28 Wilkin D, Smith AG. Variation in general practitioners' referral rates to consultants. I R Coll Gen Pract 1987;37:350-3.

29 Jewell D, Hope J. Evaluation of a nurse-run hypertension clinic in general practice. Practitioner 1988;232:474-87.

30 Charlton I, Charlton G, Broomfield J, Mullee M. Evaluation of peak flow and symptoms only self management plans for control of asthma in general practice. $B M \mathcal{F} 1990 ; 301: 1355-9$.

31 Singh BM, Holland MR, Thorn PA. Metabolic control of diabetes in general practice clinics: comparison with a hospital clinic. $B M 7$ 1984;289-726-8.
32 Hart JT, Stilwell B, Muir Gray JA. Prevention of coronary heart disease and stroke. London: Faber, 1988

33 Marsh GN. "Curing" minor illness in general practice. BMF 1977;ii: 1267-9.

34 Stott NCH. Management and outcome of winter URTI's in children aged $0-9$ ears. $B M \mathcal{F} 1979 ; i \cdot 29-3$

35 Rawlins MD. Extending the role of the community pharmacist. $B M \mathcal{J}$ 1991;302:427-8.

3 Pharmaceutical Services Negotiating Committee. The pharmacist's charter extending the role of the pharmacist in the provision of health care to the community. Aylesbury: Pharmaceutical Services Negotiating Committee, 1987.

37 Grant GB, Gregory DA, van Zwanenberg TD. A basic formulary for general practice. Oxford: Oxford University Press, 1987.

38 Royal College of General Practitioners Northern Ireland Faculty. Practice formulary, 1988-1990. London: RCGP, 1988.

39 Marsh GN. Stringent prescribing in general practice. BMf 1981;283:1159-60.

40 Balint M, Hurst J, Joyce D, Marinker M, Woodcock J. Treatment or diagnosis: a study of repeat prescriptions in general practice. London: Tavistock, 1970.

41 Difford F. Reducing prescribing costs through computer controlled repeat prescribing. I R Coll Gen Pract 19984;34:658-60.

42 Fowler G, Fullard E, Gray JAM. The extended role of practice nurses in preventive health care. In: Bowling A, Stilwell B, eds. The nurse in family practice. London: Scutari, 1988.

43 Cater L, Hawthorn P. Survey of practice nurses in the UK - their extended roles. In: Bowling A, Stilwell B, eds. The nurse in family practice. London: Scutari, 1988

44 Marsh GN, Chew C. Well man clinic in general practice. BMF 1984;288: 200-1

45 Marsh GN, Channing DM. Narrowing the health gap between a deprived and an endowed community. BMF 1987;296:173-6

46 Tant D. Personal lists. $\mathcal{F} R$ Coll Gen Pract 1985;35:507-9.

47 Pereira Gray DJ. The key to personal care. $\mathcal{F} R$ Coll Gen Pract 1979;29:666-78.

48 Preece JF, Hearson JF. The synopsis record card: a stepping stone to the computer. $\mathcal{F} R$ Coll Gen Pract 1986;36:564-6.

49 Preece J. The use of computers in general practice. 2nd ed. London: Churchill Livingstone, 1990.

50 Aylett $M$. Computerised repeat prescriptions: simple system. BMF 1985;290: $1115-6$.

51 Perrin EC, Goodman HC. Telephone management of acute paediatric illness. $N$ Engl f Med 1978;298:130-5.

52 Radeck SE, Neville RE, Girard RA. Telephone patient management by primary care physicians. Med Care 1989:27:817-22.

53 Curtis P. Eens S. Doctor-patient communication on the telephone. Canadion Family Physician 1989;35:123-8.

54 British Medical Association. General practitioner services: GMSC's guidelines on practice booklets. London: BMA, 1986

55 Mead M. How to produce a practice leaflet. Update 1990;40:137-40.

56 Department of Health. Statistics for general medical practitioners in England and Wales: 1978-1988. Statistical Bulletin 1990;4:9-15.

57 Roland M. Is there a case for smaller lists? I R Coll Gen Pract 1987;37:481-3. $8 \mathrm{Knight} R$. The importance of list size and consultation length as factors in general practice. I $R$ Coll Gen Pract 1987;37:19-22.

59 Butler JR, Calnon MW. List size and use of time in general practice. $B M \gamma$ 1987;245:1383-6.

60 Fleming DM, Lawrence MSTA, Cross KW. List size, screening methods and other characteristics of practices in relation to preventive care. $B M \mathcal{J}$ $1985 ; 291: 869-72$

\section{MATERIA NON MEDICA}

\section{When the wind blows}

"They've called it Brendan," said my Irish radiologist colleague as we sat on the Tuesday morning shuttle bus to work. "What a daft name for a typhoon. If it's an Irish typhoon there's no telling what it will do."

"Strong Wind Signal Three" was hoisted that afternoon. By the end of the clinic it was rumoured that "Storm Signal Eight" would be hoisted at $9 \mathrm{pm}$. Friends telephoned my wife to ensure that we had a good supply of food in our flat. My colleagues informed me that once Signal Eight had been declared the hospital would effectively close to all but emergencies. It would be potentially dangerous to go out, so only those on call would be expected to go to work (but I was on call).

The radio news at $9 \mathrm{pm}$ said that Storm Signal Eight had just been hoisted. On the midnight news a Royal Observatory spokesman sounded quite excited. Brendan was now $100 \mathrm{~km}$ to the south east, and was heading north west directly for the Pearl River Estuary at about $22 \mathrm{~km}$ an hour. It was expected to arrive at Hong Kong at about $5 \mathrm{am}$. People should put up storm shutters if they had them, turn off their air conditioners (to lessen the risk of their being sucked out of the wall), keep away from windows, and be ready to enter their prepared shelter (where was that?). Storm Signal Ten would be hoisted, and hurricane force winds with gusts up to $220 \mathrm{~km}$ an hour

could be expected. It was now quite cool and raining hard. The wind was very noisy, with trees swinging viciously. Could it get worse? We moved the children's beds away from the windows and debated why we had ever come to Hong Kong.

The predicted further deterioration in the weather never occurred. At 7 am it was announced that Signal Eight was still in operation. During the night Brendan had changed direction to the west, and was now $110 \mathrm{~km}$ south west of Hong Kong and crossing the coast of mainland China near Macau. The mean wind speed in Hong Kong was still greater than $63 \mathrm{~km}$ an hour, and people were still advised not to go outdoors. So far 16 people had attended hospital because of injuries sustained by flying objects, and 40 people had been evacuated from their homes.

By 10 am Brendan had been downgraded back to Signal Three, and from our windows we could see the traffic on the Tolo Highway increase almost immediately. Numerous fallen trees hindered my journey to work. It was now an unusually cool $27^{\circ} \mathrm{C}$, with $92 \%$ humidity, and life was returning to normal.

The lunchtime news said that two people had been killed in Macau. "That was just a small one," my colleagues said. -GARETH JOHN, visiting lecturer in otolaryngology, Hong Kong 